\title{
Pleistocene sedimentation and paleogeography reconstruction for the Eastern coast of the Middle Baikal
}

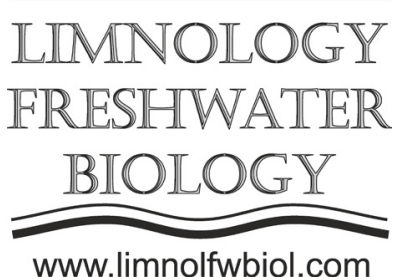

\author{
Kolomiets V.L. ${ }^{1,2 *}$, Kononov E.E. ${ }^{3,4}$, Rasskazov S.V. ${ }^{5,6}$ \\ ${ }^{1}$ Geological Institute SB RAS, Sakhyanovoy str., 6a, Ulan-Ude, 670047, Russia \\ ${ }^{2}$ D. Banzarov Buryat State University, Smolina str., 24a, Ulan-Ude, 670000, Russia \\ ${ }^{3}$ V.B. Sochava Institute of Geography SB RAS, Ulan-Batorskaya str., 3, Irkutsk, 664033, Russia \\ ${ }^{4}$ Limnological Institute, Ulan-Batorskaya str., 3, Irkutsk, 664033, Russia \\ ${ }^{5}$ Institute of the Earth's Crust SB RAS, Lermontov str., 128, Irkutsk, 664033, Russia \\ ${ }^{6}$ Irkutsk State University, Karl Marx str., 1, Irkutsk, Russia
}

\begin{abstract}
At the bottoms of intermountain basins on the eastern coast of the Middle Baikal, Pleistocene sedimentation was dominated by fluvial and lacustrine deposits. High sedimentary terraces accumulated mainly in the alluvial-lacustrine environment, whereas the lower ones originated in river conditions. Episodes of the Baikal level rise were corresponded with the four phases of tectonic reactivations that accompanied with the Baikal water ingressions into river valleys.
\end{abstract}

Keywords: intermountain basin, terrace complex, sedimentation, tectonic reactivation, ingression of Baikal waters

\section{Introduction}

Lake Baikal that occupies the central part of the Baikal Rift Zone infill three geomorphologically individual basins: Southern, Central, and Northern. The Central one is located between the delta of the Selenga River and the Ushkany Islands. A mountainous relief on its eastern coast is complicated by a chain of negative morphostructures, the largest of which are the Nalimovka, Nizhnyaya Turka, and Kotokel basins. The aim of this study is to determine conditions of Pleistocene sedimentation in these basins of the Baikal coast.

\section{Research methods}

In the lithological and stratigraphic study of sedimentary sections and paleogeographic reconstructions, sieve granulometric analysis was used, the main processing of which were graphic and statistical methods (Shvanov, 1969). Hydrodynamic signatures of paleoriver flows were defined by paleopotamological analysis (Kolomiets, 1998, 2010). Ages of loose sediments were obtained using a radiothermoluminescent (RTL) method (Perevalov, Rezanov, 1997).

\section{Results}

The Nalimovka basin has the widest part that stretches over $6.5 \mathrm{~km}$ along the shore of the Bezymyannaya Bay of Lake Baikal and funnelshaped is getting more narrow $17-18 \mathrm{~km}$ upstream of the Nalimovka River. This basin shows the late Eopleistocene - Middle Pleistocene (VII-IV) erosionalaccumulative levels (EAL) and III-II terraces.

The late Eopleistocene (VII) EAL, which is as high as $120-140 \mathrm{~m}$, exhibits fine-medium-grained sands that yielded an RTL age of 1,000,000 $\pm 90,000$ years (GIN SB RAS-399). The coefficient of variation $(v=0.52-0.64)$ determines the origin of sediments as alluvial-lacustrine one. From paleopotamological data, it is inferred that their accumulation took place in low-flow, shallow (up to $2 \mathrm{~m}$ ) lacustrine reservoirs with a moderate dynamic regime of flows that transported sediments. Paleorivers had a flat type of natural wandering channels (Froude number $\mathrm{Fr} \leq 0.1$ ).

The Early-Middle Pleistocene (VI) EAL, which is $60-80 \mathrm{~m}$ high, also presents fine-medium-grained sands. The slightly elevated coefficient of variation $(v=0.68-0.70)$ corresponds to the alluvial-lacustrine genotype. Sedimentation occurred in shallow stable low-flow lake-like reservoirs by a network of plain-type paleostreams $(\mathrm{Fr} \leq 0.1)$.

The 40-50 m high (V) EAL was accumulated in the first half of the Middle Pleistocene. Its finemedium-grained sands show a set of fractions and their percentage (and, therefore, their statistical and paleopotamological signatures) similar to those of the higher erosional-accumulative levels of the basin that

*Corresponding author.

E-mail address: kolom@ginst.ru (V.L. Kolomiets) 
demonstrate uniform sedimentation environments in the study area during this time interval of the Quaternary.

The IV EAU (2nd half of the Middle Pleistocene, 25-35 m) is widespread within the extended part of the basin. A sandy material is fine- to coarse-mediumgrained. The coefficients of variation $(v=0.55-$ 0.69) show a mixing field of lacustrine and alluvial sedimentation environments, but taking into account proximity to Lake Baikal and that they do not exceed the upper limit of 0.8 units for sediments of lacustrine genesis, these deposits are considered lacustrine ones accumulated in the highly dynamic conditions of the zone of the coastal-beach facies.

The Late Pleistocene accumulative terraces (III 15-25 $\mathrm{m}$ and II - 9-12 m) show RTL ages of $>42,000$ years (GIN SB RAS-396) and of $>84,000$ years (GIN SB RAS-397), respectively. These form a wide front along the coast of Lake Baikal throughout its length. Statistical parameters of their fine- and coarse-mediumgrained sands indicate some differences in dynamics of sedimentary basins - a more equilibrium eventfulness of sediment accumulation of the III terrace and an increased sediment accumulation dynamics of the II terrace associated with a possible increase in the amount of free water in the Karga period as compared to the previous Yermakovsky period.

The Nizhnyaya Turka basin occupies the near estuarine part of the lower current of the Turka River. The most representative section of loose sediments is observed in the $60-80 \mathrm{~m}$ high watershed between the Turka and Kotochik rivers. Granulometrically, the sediments are represented by medium-grained sands with a subordinate role of other (fine- and coarsegrained) varieties. The textural and structural features of the sediments indicate the aquatic character of their transport and deposition. Their almost uniform composition indicates retained energy conditions of sedimentation environment. From hydrodynamic parameters, it is inferred that sedimentation occurred in a shallow, flowing lake-like water reservoir (setting of coastal facies).

The Kotokel basin has an oval shape slightly elongated to north and south. Most of the basin is occupied by Lake Kotokel. A dry bottom of the basin slightly inclined towards this lake is covered by loose Quaternary sediments that are correlated with those of the EAU and accumulative terraces of the Nalimovka basin.

Eopleistocene-Lower Pleistocene sediments belong to the 80-120 m high VII EAL. The exposed upper part of a sequence is represented by silty-fine-mediumgrained sand. Coefficients of variability $(0.4<v<0.8)$ correspond to the interval of mixed alluvial-lacustrine genesis. The sediments were deposited in a shallow (up to $2 \mathrm{~m}$ ) low-flow permanent reservoir.

The 50-80 m high Early-Middle Pleistocene (VI) EAL is composed of medium-fine-grained material. In a vertical section, the stratum is inhomogeneous. There are frequent interlayers and lenses of dark silts, brown thin-layered sandy loams, brown, grey, plastic bluish-grey clays. The sediments show spots and layer- by-layer enrichment with iron oxides and hydroxides as well as widespread inclusions of detrital organic material. The sand variation coefficient $(v=0.5-0.7)$ demonstrates a mixed (alluvial-lacustrine) character of the sedimentation basin with the occurrence of shallow-flowing reservoirs and stepwise ones with slow hydrodynamic parameters of the plain-type channel flows.

The 25-35 m high Middle Pleistocene (IV) EAL and 17-25 $\mathrm{m}$ high Upper Pleistocene (III) terrace show fine-medium-grained sands. The coefficient of variation corresponds to the inhomogeneous aquatic genesis. According to paleohydrological data, the depths of such paleochannels did not exceed $2.5 \mathrm{~m}$.

\section{Discussion and conclusion}

In the analysis of the character of sedimentation in the Nalimovka basin, we infer that a lacustrine regime of sedimentation took place here already in the late Eopleistocene. The material was delivered by small flat-type water channels. Its deposition took place mainly in the submerged delta state. Similar conditions took place throughout the entire Middle Pleistocene. The depression repeatedly became a paleo-bay of Lake Baikal along its entire length, similar to modern small hollow (shallow bays). Late Pleistocene sedimentation was predominantly lacustrine. The depression was filled with water up to the tectonic intradepression sill and, therefore, it was exhibited the Nalimovka paleohollow.

In sands from the Nizhnyaya Turka basin, spicules of sponges of two families were found: the family Spongillidae: Ephydatia fluviatilis L., Spongilla sp. from continental water reservoirs and the family Lubomirskiidae - Lubomirskia baikalensis Pall. (Dyb.), which is endemic Baikal sponges (Martinson, 1951). The occurrence of these species shows the accumulation of sandy strata in the lake reservoir connected with Lake Baikal. Physical and geographical conditions of this paleoreservoir were similar to those in the modern Baikal shallow bays.

At the Eopleistocene - Pleistocene boundary, a stationary shallow low-flow lacustrine reservoir appeared in the Kotokel depression, in which, along with the dominance of limnic sedimentation conditions in the coastal zone of the water area, there were also alluvial ones due to penetration of palaeo-low-water currents into the basin. This kind of situation existed until the beginning of the Middle Pleistocene, in the first half of which there was a repeated degradation of the lake system with its disintegration into small separate stagnant reservoirs, in which bog and lacustrine-bog sediments accumulated (clay interlayers and lenses enriched with organic matter in the VI EAL). This could be caused by climate aridization in mountains of the Baikal region resulted in limited water flow and rapidly degraded lakes of the small basin. From the end of the Middle to the end of the Late Pleistocene, a predominantly limnic environment of sedimentation was restored in the basin, because the IV and III sedimentary levels show no differences in paleohydrological regime. 
The dominated sedimentary strata of the water origin in high levels indicate repeated ingressions of Baikal water into valleys of the river flowed to the Baikal caused by differentiated tectonic motions that affected the Baikal region in the Early Primorye (1.3-1.1 $\mathrm{Ma})$, Late Primorye (0.8-0.6 Ma), Khubsugul (0.6-0.4 $\mathrm{Ma})$, and Tyya (0.15-0.1 $\mathrm{Ma}$ ) reactivations. In the Late Pleistocene, the ingressed water was descended. Low river terraces formed in dry basins. In basins open to Lake Baikal, separate lacustrine strata accumulated due to short-term rises of Baikal water levels or existence of relict lakes: the remains of large Middle Pleistocene water reservoirs.

\section{References}

Kolomiets V.L. 1998. Reconstruction of parameters of paleoflows from fossil sediments. Bulletin of Buryat University. Series 3: geography, geology 2: 92-100. (In Russian)

Kolomiets V.L. 2010. Sedimentogenesis of the Pleistocene aquatic complex and the conditions for the formation of nonmetallic raw materials formation in dry basins of the Baikal rift zone. Dissertation ... cand. geological-mineralogical sciences. Irkutsk. (In Russian)

Martinson G.G. 1951. Tertiary fauna of mollusks of the Eastern Pribaikalia. Proceedings of the Baikal Limnological Station. V. XIII. Moscow, USSR Academy of Sciences, pp. 5-92. (In Russian)

Perevalov A.V., Rezanov I.N. 1997. The first experience of radiothermoluminescence dating of anthropogenic deposits of South-West Transbaikalia. Russian Geology and Geophysics 38 (7): 1245-1251. (In Russian)

Shvanov V.N. 1969. Sandy rocks and methods of their study. Leningrad: Nedra Publisher. (In Russian) 